\title{
Event centrality in trauma and PTSD: relations between event relevance and posttraumatic symptoms
}

\author{
Thiago Loreto Garcia da Silva*, Julia Candia Donat, Pânila Longhi Lorenzonni, Luciana Karine de Souza, \\ Gustavo Gauer and Christian Haag Kristensen
}

\begin{abstract}
Recent investigations propose that cognitive characteristics of autobiographical memory significantly interact with Posttraumatic Stress Disorder (PTSD). A traumatic event becoming more or less central in a person's identity and life story might influence development of the disorder. Studies show high correlations between event centrality (EC) and PTSD. Participated in this study 68 treatment-seeking individuals referred to a specialized service for suspected trauma-related disorder: 39 matched criteria for PTSD and 29 were exposed to trauma without PTSD. Our aims were to explore how the groups differ regarding EC, depression, anxiety, posttraumatic cognitions, PTSD symptom severity, and peritraumatic dissociative experience; and how distinctively EC interacts with the measures in each group. The PTSD group had higher scores in all variables but dissociation. EC correlated with overall PTSD symptoms only in the PTSD group and with dissociation only in the no-PTSD group. Findings support a model emphasizing the role of memory processes in PTSD. People exposed to trauma who developed PTSD had the memory of the traumatic experience more intensively governing their sense of self and thus eliciting more negative cognitive reactions. As EC facilitates recollection of the traumatic event, it could also mediate a semantization process that reinforces and increases posttraumatic symptoms.
\end{abstract}

Keywords: Event centrality, Trauma, Post-traumatic stress disorder, Autobiographical memory

\section{Background}

Most people will experience highly stressful events at some point in their lives. Epidemiological studies estimate that 40 to $90 \%$ of the general population experiences or witnesses at least one traumatic event across the life span (Creamer et al. 2001; Kessler et al. 1995). In Brazil, a recent epidemiological study in two brazilian capital cities showed that $90 \%$ of the population faced a trauma in life and approximately $11 \%$ had Posttraumatic Stress Disorder (PTSD). In this study all mental disorders were associated with the occurrence of traumatic events (Ribeiro et al., 2013).

Although many studies assess psychological trauma and the symptoms of its related disorders, they rarely analyze the wide range of possible human reactions in face of traumatic experiences (Bonanno et al. 2011), as well as their cognitions. In terms of cognitive content,

\footnotetext{
* Correspondence: th.loreto@gmail.com

Centre of Studies and Research in Traumatic Stress Post-Graduate Program in Psychology, Pontifícia Universidade Católica do Rio Grande do Sul, Av. Ipiranga, 6681 - Prédio 11, Porto Alegre, RS, Brazil
}

traumatic events might become central in the organization of an individual's identity and life story (Berntsen \& Rubin, 2006). Thus defined, event centrality (EC) is a critical factor in the autobiographical cognitive processing of stressful, emotional, and traumatic events.

One of the integrative human capacities to adapt to changes and difficulties in the environment is the cognitive ability to organize personally experienced events in terms of self-reference. This process allows for extracting meaning from them. It is a complex phenomenon well studied via Autobiographical Memory (AM) models (Bluck et al. 2005; Rubin, 1982). AM entails cognitive processes involving the recollection of events that belong to an individual's past. They differ from episodic memories for its significant interaction with the individual's life narrative (Rubin, 2006).

As it allows processing information from past events, AM plays an important role for human adaptation to different types of life events. To achieve this, AM grants 
the construction of a dynamic transitory mental representation with specific event-related information, selfknowledge and goal-driven control processes (Conway \& Pleydell-Pearce, 2000). Therefore, AM and the evolutionary self might have enabled humans to deal with increasingly complex social environments, expanding the range of our actions in the world (Damasio, 1999). Moreover, AM is central for managing emotions, developing personhood and the sense of being oneself as well as a culturally embedded individual (Fivush, 2011).

An AM system encodes and organizes a broad scope of possible events. Nonetheless, research suggests that culturally shared events, especially emotionally positive personal events (e.g. marriage, graduation, the birth of one's child), are better retained and more often recollected than others (Berntsen \& Rubin, 2002). That tendency plays a role in helping people to cope positively with present life events, whilst also enhancing affect regulation (Raes et al. 2003; Walker et al. 2003).

On the influence of emotion on memory, evidence suggests that some AM events are intrinsically more stressful than others. Neuroimaging studies and cognitive experiments account for the well-established powerful influence of emotional arousal on memory consolidation and recall availability (Labar \& Cabeza, 2006). Following this path, and in contrast to theories that depict stressful, traumatic memories as a "special" or "disrupted" element in the AM system, the system's own basic functioning could explain the negative effects of dealing with stressful events on memory (Rubin et al. 2008b).

If stressful events are more accessible to memory and more often recovered, they might assume a central position in a person's identity. This could alter the tendency for a more positive life events narrative (Boals, 2010), making way for traumatic events that come to be central to exert negative impacts on mental health (Berntsen et al. 2011). The negative experiences turn into a point of reference for further perceptions, interpretation of new events and everyday inferences. Consequently, it is likely that the person will overestimate the frequency of such events and the possibility of experiencing them, and happenings alike, in the future. The overestimation yields unnecessary concerns and precautions, such as avoiding certain classes of events because of the perception that they may lead to specific risks (Berntsen \& Rubin 2006a, b). Corroborating with these hypotheses, the EC is associated with posttraumatic (Berntsen \& Rubin 2006a, b) and depressive (Boals, 2010) symptoms, contradicting the widespread view that the traumatic memory is poorly integrated into one's life. Instead, enhanced or overintegration appears to be the case (Berntsen \& Rubin, 2007).

Posttraumatic Stress Disorder (PTSD) is a severe distress following a traumatic experience after at least one month, becoming possibly chronic (American Psychiatric Association, 2013; Breslau et al., 1998). PTSD symptoms include intrusive memories relative to the stressful event, dissociative reactions, negative changes in perception of self and others, avoidance to cognitive or behavioral stimuli that may refer to the event, increased arousal and anxiety, sleeping problems, and increased startle response (American Psychiatric Association 2013).

PTSD symptoms are strongly related to memory functioning. Rubin et al. (2008a) posit a mnemonic model of PTSD based on predisposing factors that affect the manner in which the event will be encoded and retrieved. Contrasting with models in which symptoms emerge by mere conditioning, the main hypothesis is that declarative long-term memory processes critically influence symptom development. Moreover, factors such as posttraumatic cognitions, event positioning in the organization of long-term memory, and coping strategies play an important role in the etiology of the disorder.

Several studies support the mnemonic model through strong correlations between EC and PTSD symptoms. Brown et al. (2010) found a .58 correlation $(p<.05)$ between in veterans from the wars in Iraq and Afghanistan. Robinaugh and McNally (2011) found .69 $(p<.001)$ in survivors of childhood sex abuse. Also, Boals et al. (2012) studied trauma events in general and observed a .31 correlation $(p<.001)$ in young adults (under 29 years-old) and a .35 among older adults (60 years and over). Yet there is an ongoing debate whether stressful memories and trauma memories in PTSD operate in a single continuum or compose different categories of memories (Sotgiu \& Rusconi, 2014).

In order to better clarify the role of centrality on the development of PTSD, one may attempt to identify, for example, different effects of EC on traumatic memories of people with and without PTSD symptoms. Following this rationale, this study aimed to investigate the role of EC on PTSD by comparing a traumatized sample without PTSD symptoms with individuals meeting criteria for this diagnosis. Specifically, we compared EC between individuals exposed to trauma with and without PTSD symptoms, and explored how distinctively EC interacts with other relevant variables (depression, anxiety, posttraumatic cognitions, PTSD symptom severity, and dissociative experience) in each group. These comparisons could bring evidence to the discussion regarding the poor/over integration of the traumatic memory. Moreover, focusing on events considered by the patients as life altering could help mental health professionals in the assessment and treatment of tipping points that at least maintain the distress (Boals \& Schuettler, 2011). 


\section{Method}

\section{Participants}

Sixty-eight victims of traumatic events (45 women, 66.2 $\%)$ composed the study sample. Public health services referred them for psychological assessment at the Centre for Studies and Research in Traumatic Stress (NEPTE) of the Pontifical Catholic University of Rio Grande do Sul (Porto Alegre, Brazil). NEPTE is a specialized center for the treatment of people who experienced traumatic events, with a cognitive behavioral therapy approach. All patients evaluated in the center within one year were considered suitable for the study, since patients with psychotic symptoms, neurological disorders and substance abuse are not allowed in the center and are therefore excluded from the study.

Mean age of participants was 38.62 (SD = 14.04) years. As for educational level, 15 participants (22.1\%) had high school degree, 13 (19.1\%) had incomplete higher education, and 11 (16.2 \%) have not completed high school. When the study took place, nearly half the sample was using psychiatric medication, mostly anxiolytics $(n=17,25 \%)$ and antidepressants $(n=15,22.1 \%)$.

\section{Procedures and measures}

The standard clinical evaluation protocol used at NEPTE has a set of instruments that includes the ones analyzed in this study. Psychologists, or trained interns, specialized in trauma-related disorders conduct assessment usually in two sessions of one and a half hour each. If the traumatic event does not come into conversation in the first session, the interviewer moves the related measures to the second section. The instruments used in the present investigation were the following, in order of administration:

Personal Data and Socio-Demographic Interview. For information such as gender, age, marital status, education and socioeconomic levels.

Trauma Interview. It evaluates different dimensions of traumatic events, such as exposure and duration (Foa et al. 2007; adapted for clinical use by the NEPTE team).

Structured Clinical Interview for DSM Disorders (SCID-I) (First et al. 1997; Brazilian adaptation by DelBen et al., 2001). This interview explores symptoms of psychiatric disorders according to DSM-IV (American Psychiatric Association 1995) diagnostic criteria. Participants were assigned to the PTSD or no-PTSD group according to criteria.

Beck Anxiety Inventory (BAI) (Beck et al. 1988, $\alpha=.92$; Brazilian version by Cunha, 2001, $\alpha=.87$ ). A 21-item measure (via 4-point Likert scale) designed to identify anxiety symptoms.

Beck Depression Inventory-II (BDI-II) (Beck et al. 1996, $\alpha=.91-.93$; Brazilian adaptation by Gorenstein et al. 2011, $\alpha=.89)$. A 21-item measure (4-point scale) to detect symptoms of depression.

Screen for Posttraumatic Stress Symptoms (SPTSS) (Carlson, 2001, $\alpha=.91$; Brazilian Portuguese version by Kristensen, 2005, $\alpha=.85)$. Based on diagnostic criteria from the DSM-IV-TR (American Psychiatric Association 2002), its 17 items (10-point scale) screen for posttraumatic symptoms via three dimensions: avoidance/numbing, re-experience, and hyperarousal.

Posttraumatic Cognitions Inventory (PTCI) (Foa et al. 1999, $\alpha=.97$; adapted for use in Brazil by Sbardelloto et al. 2013). It examines post-traumatic cognitions about the world, about others, and self-blame via 36 items rated on a 7 -point scale.

Peritraumatic Dissociative Experiences Questionnaire (PDEQ) (Marmar et al. 2004, $\alpha=.85$; adapted for the Brazilian population by Fiszman et al., 2005). This selfreport, 10-item questionnaire (5-point scale) assesses dissociative reactions that took place during the traumatic event.

Centrality of Event Scale (CES) (Berntsen \& Rubin, 2006, $\alpha=$.94; Brazilian version from Gauer et al. 2013, $\alpha=.95$ ). This 20-item instrument (5-point scale) measures how central the memory of a specific event is in a person's life history, as well as maladaptive attributions to the event.

\section{Results}

On average, participants had experienced 3.17 (SD = 2.162) traumatic events over their lives. Among the most frequent types were assault/robbery $(n=15,22.1 \%)$, sexual violence $(n=7,10.3 \%)$, and motor vehicle accidents $(n=6,8.8 \%)$. The SCID-I identified 39 (57.5 \%) clients with symptoms of PTSD (hereon referred to as the PTSD group); the remaining 29 composed the noPTSD group.

Sample distributions of the measures were predominantly non-normal, suggesting non-parametric statistics. Table 1 presents the results for Mann-Whitney tests targeting group differences. As hypothesized, we found differences between groups concerning EC, with the PTSD group scoring higher. In addition, the PTSD group scored higher on all other variables under analysis: posttraumatic cognitions, peritraumatic dissociation, and depressive, anxiety and posttraumatic symptoms. All group differences were significant but for one variable: peritraumatic dissociation.

Our second aim was to find out how EC interacts with the other variables in each group. Table 2 shows correlations among EC, posttraumatic cognitions, peritraumatic dissociation, and depressive, anxiety and posttraumatic symptoms for the PTSD group; Table 3, for the noPTSD group.

Regarding the PTSD group, Table 2 shows significant correlations between EC and posttraumatic cognitions, 
Table 1 Mann-Whitney Test for PTSD and no-PTSD Groups

\begin{tabular}{|c|c|c|c|c|c|c|c|}
\hline & \multicolumn{2}{|l|}{ PTSD } & \multicolumn{2}{|c|}{ no-PTSD } & \multirow[b]{2}{*}{ DF } & \multirow[b]{2}{*}{ U } & \multirow[b]{2}{*}{$p$} \\
\hline & $\bar{M}$ & $\mathrm{SD}$ & $\bar{M}$ & SD & & & \\
\hline CES & 4.07 & .688 & 3.37 & 1.08 & 66 & 335 & .011 \\
\hline PDEQ & 2.99 & 1.01 & 2.53 & .913 & 64 & 366 & .069 \\
\hline PTCI & 4.12 & 1.07 & 3.02 & 1.18 & 61 & 234 & .002 \\
\hline SPTSS & 6.75 & 1.81 & 4.24 & 2.08 & 61 & 193.5 & .000 \\
\hline SPTSS-AN & 6.09 & 1.78 & 4.29 & 2.07 & 66 & 272.5 & .001 \\
\hline SPTSS-HA & 7.10 & 2.08 & 4.52 & 2.65 & 66 & 251.5 & .000 \\
\hline SPTSS-RE & 7.32 & 2.48 & 3.91 & 2.58 & 66 & 209 & .000 \\
\hline $\mathrm{BAl}$ & 30.00 & 14.03 & 17.80 & 11.90 & 66 & 295.5 & .002 \\
\hline BDI-II & 29.05 & 10.50 & 20.10 & 12.20 & 65 & 301 & .005 \\
\hline
\end{tabular}

Note. PTSD Post-traumatic stress disorder, CES Centrality of events scale, PDEQ Peritraumatic dissociative experience questionnaire, PTCI Posttraumatic cognitions inventory, SPTSS Screen for posttraumatic stress symptoms, AN Avoidance/ numbing subscale, $H A$ Hyperarousal subscale, RE Re-experience, $B A$ I Beck anxiety inventory, $B D I-I I$ Beck Depression inventory II. Two-tailed $\mathrm{p}$ levels

symptoms (overall, hyperarousal, and re-experience), anxiety, and depression. There were no significant correlations in the relationship of EC with peritraumatic dissociation, nor with symptoms of avoidance/numbing, in participants in the PTSD group.

As for the no-PTSD group (Table 3), EC has significant correlations with peritraumatic dissociation, posttraumatic cognitions, re-experience symptoms, anxiety, and depression. There were no significant correlations for EC and the overall SPTSS score, the avoidance/ numbing score, and the hyperarousal score.

Taken together, Tables 2 and 3 display similar correlation patterns for EC in terms of posttraumatic cognitions, avoidance/numbing, and anxiety. Notwithstanding the non-significant correlations with avoidance/numbing in both groups, there were positive significant correlations with posttraumatic cognitions (PTSD group $=.335$; no-PTSD $=.436)$ and with anxiety $(\mathrm{PTSD}=.349$; no-

Table 2 Spearman correlations in the PTSD group

\begin{tabular}{lllllllll}
\hline & 1 & 2 & 3 & 4 & 5 & 6 & 7 & 8 \\
\hline 1. CES & - & & & & & & & \\
2. PDEQ & .317 & - & & & & & & \\
3. PTCI & $.335^{*}$ & $.625^{* *}$ & - & & & & & \\
4. SPTSS & $.423^{* *}$ & $.485^{* *}$ & $.623^{* *}$ & & & & & \\
5. SPTSS-AN & .304 & $.473^{* *}$ & $.577^{* *}$ & $.878^{* *}$ & & & & \\
6. SPTSS-HA & $.463^{* *}$ & $.427^{* *}$ & $.481^{* *}$ & $.860^{* *}$ & $.636^{* *}$ & - & & \\
7. SPTSS-RE & $.359^{*}$ & $.377^{*}$ & $.581^{* *}$ & $.887^{* *}$ & $.648^{* *}$ & $.664^{* *}$ & - & \\
8. BAI & $.349^{*}$ & $.442^{* *}$ & $.540^{* *}$ & $.588^{* *}$ & $.459^{* *}$ & $.493^{* *}$ & $.590^{* *}$ & - \\
9. BDI & $.371^{*}$ & $.623^{* *}$ & $.798^{* *}$ & $.734^{* *}$ & $.674^{* *}$ & $.696^{* *}$ & $.566^{* *}$ & $.533^{* *}$ \\
\hline
\end{tabular}

Note. PTSD Post-traumatic stress disorder, CES Centrality of events scale, PDEQ Peritraumatic dissociative experience questionnaire, PTCI Posttraumatic cognitions inventory, SPTSS Screen for posttraumatic stress symptoms, AN Avoidance/ numbing subscale, HA Hyperarousal subscale, RE Re-experience, $B A$ I Beck anxiety inventory, $B D I-I /$ Beck depression inventory $\mathrm{Il}^{*}{ }^{*}=p<.05 ;{ }^{* *}=p<.01$
Table 3 Spearman correlations in the no-PTSD group

\begin{tabular}{lllllllll}
\hline & 1 & 2 & 3 & 4 & 5 & 6 & 7 & 8 \\
\hline 1. CES & - & & & & & & & \\
2. PDEQ & $.473^{*}$ & - & & & & & & \\
3. PTCl & $.436^{*}$ & $.544^{* *}$ & - & & & & & \\
4. SPTSS & .306 & $.442^{*}$ & $.774^{* *}$ & - & & & & \\
5. SPTSS-AN & .204 & $.401^{*}$ & $.697^{* *}$ & $.873^{* *}$ & - & & & \\
6. SPTSS-HA & .186 & $.386^{*}$ & $.665^{* *}$ & $.902^{* *}$ & $.702^{* *}$ & - & & \\
7. SPTSS-RE & $.418^{*}$ & .364 & $.619^{* *}$ & $.834^{* *}$ & $.546^{* *}$ & $.655^{* *}$ & - & \\
8. BAI & $.389^{*}$ & $.400^{*}$ & $.736^{* *}$ & $.749^{* *}$ & $.581^{* *}$ & $.742^{* *}$ & $.638^{* *}$ & - \\
9. BDI & $.501^{* *}$ & $.379^{*}$ & $.768^{* *}$ & $.715^{* *}$ & $.535^{* *}$ & $.579^{* *}$ & $.759^{* *}$ & $.793^{* *}$ \\
\hline
\end{tabular}

Note. PTSD Post-traumatic stress disorder, CES Centrality of events scale, PDEQ Peritraumatic dissociative experience questionnaire, PTCI Posttraumatic cognitions inventory, SPTSS Screen for posttraumatic stress symptoms, AN Avoidance/ numbing subscale, $H A$ Hyperarousal subscale, RE Re-experience, $B A$ I Beck anxiety inventory, $B D I-I /$ Beck depression inventory $\mathrm{II}^{*}{ }^{*}=p<.05 ;{ }^{* * *}=p<.01$

PTSD $=.389)(p<.05)$. Another group distinction via EC was peritraumatic dissociations: a significant positive correlation in participants without PTSD symptoms $(r=.473$; $p<.05)$, and a non-significant positive correlation in the PTSD group $(r=.317)$.

As to depressive symptoms, both groups had significant and positive correlations with EC. Nevertheless, their correlations were notably different: .371 for the PTSD group, and .501 for the no-PTSD.

Another interesting result was how remarkably the PTSD group and the no-PTSD group differed in terms of the relationship between EC, overall PTSD symptoms, and hyperarousal symptoms. While both variables correlated significantly with EC in the PTSD group (.423 and .463 , respectfully) $(p<.01)$, no significant correlations emerged with the no-PTSD group.

\section{Discussion}

This study aimed to investigate differences between individuals with symptoms of PTSD and individuals exposed to traumatic events but without PTSD symptoms. We were interested in examining how central a traumatic event becomes in the life of a person that experienced a highly stressful event. We also explored how EC and other variables related to cognitive processing of the event might influence the presence of PTSD symptoms.

We assessed PTSD symptoms, posttraumatic cognitions, peritraumatic dissociations, anxiety and depressive symptoms, and EC in 68 clients who sought psychological care at NEPTE. PTSD criteria detected that $57.5 \%$ of the clients match the criteria for the disorder. Regard of that incidence level must take into account that referral by public health care to a service specialized in stress and trauma was due to signals of traumatic experience and a probable trauma-related disorder.

Our main findings indicate that EC interacts with trauma distinctly in participants whose symptoms match 
the disorder from those who does not. That result is in line with what Berntsen and Rubin (2007) and Boals (2010) found regarding the noteworthy association between centrality of events and posttraumatic symptoms severity. In addition, CES score and overall SPTSS score correlated significantly in the PTSD group, but not in the no-PTSD group. That points to EC as an important mediator factor for the development of PTSD.

Clients who reached criteria for PTSD presented higher scores in all variables under examination, in comparison to the no-PTSD group. That indicates that the groups were very distinct concerning trauma-related cognitive processing, in accordance with Rubin et al. (2008a). Nonetheless, peritraumatic dissociations did not differ significantly between groups according to the PTSD criteria used in the study. To understand this, we first must consider the retrospective nature of this dissociation report, and the mnemonic processes interfering in the episodic retrieval of the event (Candel \& Merckelbach, 2004). In this view, what is labeled as dissociation might in fact be natural distortions in retrieving emotional memories. Therefore, no special mechanisms explanations for trauma memories are needed (Rubin et al. 2008a, b). In this sense, considering that in our sample group differences were more pronounced in centrality than in dissociation, we estimate that the association between these two variables occurs only up to some point, decreasing interaction as other factors come into play, such as higher posttraumatic symptoms and more memory rehearsal. This hypothesis is based on the statement that when a memory is more emotional, central, and constantly rehearsed, some specific sensory details of the scene are reinforced (Rubin et al. 2008a, b).

A semantization mechanism might explain the findings on posttraumatic symptoms, depression, and dissociation. While an event is repeatedly re-experienced, the memory is consolidated in long-term system in a conceptual and semantic organization, and episodic aspects over the event will be fading (Piolino et al. 2007). Centrality of events, as an organizational feature that facilitates recollection, could be mediating the semantization process. Therefore, it is plausible that a central traumatic event more often recovered (by feedback) reinforces depressive and hyperarousal symptoms, increasing suffering up to a diagnostic level. Those propositions support the mnemonic model of PTSD (Rubin et al. $2008 \mathrm{a}, \mathrm{b})$, and do not require special mechanisms for trauma and PTSD to obtain.

Regarding correlation patterns in the PTSD group, EC was associated with the hyperarousal and re-experience symptoms, but not with avoidance/numbing. These results are consistent with previous findings indicating that centrality relates more to rumination and rehearsal than to memory avoidance or thought suppression (measured here by the avoidance/numbing subscale of SPTSS) (Newby \& Moulds, 2011; Rubin et al. 2011). Our study thus corroborates the proposition that trauma victims whose symptoms match the criteria for PTSD are more inclined to have the memory of the traumatic experience governing their sense of self and eliciting more negative cognitive reactions as rumination and rehearsal in dealing with difficulties throughout life.

In the no-PTSD group, EC correlated significantly with peritraumatic dissociation, posttraumatic cognitions, anxiety, depression, and re-experiencing symptoms. Regarding peritraumatic associations, the aforementioned discussion concerning mean differences between groups withstands. In addition, it is noteworthy that the re-experience subscale of SPTSS, and not the overall symptoms nor the other subscales, correlated significantly with centrality even though this group did not reach the criteria for PTSD. That suggests that re-experience seems to favor a traumatic event occupying the center of an individual's identity and life story. However, that specific association between cognitive content and symptoms does not necessarily cause the disorder, even in the presence of posttraumatic cognitions, which also correlated significantly with EC in the no-PTSD group. Complementary, the absence of correlation between centrality and SPTSS hyperarousal symptoms distinguishes this group from the clinical group. That reinforces a hypothetical role for this set of symptoms in the development of PTSD.

Centrality was associated with depressive symptoms in both groups. Previous research with undergraduate students had also found this association, although usually via low correlations (Boelen, 2009). We observed this in our results with the PTSD group, but not with the noPTSD participants. In a clinical sample without PTSD patients, Newby and Moulds (2011) compared groups of depressed, recovered-depressed, and never-depressed participants and found no difference in EC. That suggests centrality might play an important role in PTSD, but not in depression.

\section{Conclusions}

Results of this study are in line with the hypothesis that trauma exerts crucial effects to the AM system. Findings support the idea that EC mediates the interaction between them, for centrality is not due to trauma. It is a basic process that pertains to the system of AM itself. In this sense, studying EC in people that experiences stressful events is relevant not only for assessment purposes, but for providing clinical psychologists with a pertinent variable in treating the consequences of trauma to mental health and quality of life. In sum, centrality is a process that matters in many disorders, as it is the case for PTSD. 
The cross-sectional and correlational nature of the present study does not allow causal inferences. Experimental and longitudinal designs would be necessary to establish causal roles for EC in PTSD, as well as for influences of rehearsal and semantization processes on centrality. In addition, our sample was strictly treatment-seeking clients. That may be a cause of increased symptom levels in the no-PTSD sample. Further studies could include samples of individuals exposed to trauma who did not seek any treatment (psychological or pharmacological), as well as non-traumatized controls to increase generalizability. Nevertheless, our results regarding EC in its correlations with other factors in two different groups contribute to establish its relevance in the relationship between experiencing and remembering a traumatic event and developing PTSD. Whether EC shows to be a moderator, influencing the strength with which factors contribute to developing PTSD, or a mediator, explaining how exactly those relationships obtain, remains one of many questions for future clinical studies.

Studies with attention to centrality in negative life events may contribute to the understanding of how AM works, but also how it deals with the information and emotional valence. People without trauma experience(s) tend to report positive events as central to their autobiographical narratives, whilst people diagnosed with depression report more events that are negative; PTSD patients may report both types as central.

Trauma is a pervasive class of human experiences. Nonetheless, it entails events thematically different from one culture to another. In Brazil, for example, wars are not typically present in the roll of themes reported by trauma victims, but urban violence. In the case of Brazilian population, the investigation of event centrality regarding urban violence events could help mental health professionals in the prevention and treatment of its negative impacts. Since our subjects were mostly assault victims, further studies could investigate if specific characteristics of such events played an important role in our results, as well as sociodemographical and other cultural characteristics.

In addition, there is already enough attention to how frequent and relevant negative memories are to PTSD in terms of etiology and treatment. However, as trauma is more frequent than the PTSD per se, it is important to understand the role of centrality for the quality of life of the population as a whole. Specifically, it is pertinent to direct attention and research efforts to approach EC aiming the large amount of people that experience trauma episodes but will not develop a disorder.

To detect the centrality of a traumatic event may help prevent the emergence of behavioral and social problems, such as anti-social behaviors, job loss, and interpersonal relationships' losses. Finally, EC is a process that requires more attention from research and professional contexts, especially for its potential in helping prevent in light of mental health and quality of life.

\section{Competing interests}

The authors declare that they have no competing interests.

\section{Authors' contributions}

$\mathrm{TL}$ and JD carried out all proceduers in this reseach (data collection and writing). All other authors carried out the data analysis and interpretation. All authors read and approved the final manuscript.

\section{Acknowledgements}

The authors acknowledge the support provided by the Pontifical Catholic University of Rio Grande do Sul, the Conselho Nacional de Desenvolvimento Científico e Tecnológico (CNPq) and the Coordenação de Aperfeiçoamento de Pessoal de Nível Superior (CAPES).

Received: 10 March 2016 Accepted: 7 April 2016

Published online: 28 April 2016

\section{References}

American Psychiatric Association. Manual diagnóstico e estatístico de transtornos mentais (DSM- $N^{T M}$ ) (4 ed.) [Diagnostic and statistical manual of mental disorders (DSM-IV) (4th ed.)]. Porto Alegre: Artes Médicas; 1995. Original published in 1994.

American Psychiatric Association. Manual diagnóstico e estatístico de transtornos mentais (DSM-IV-TR ${ }^{T M}$ ) (4 ed.), Texto Revisado [Diagnostic and statistical manual of mental disorders (4th ed., text rev.)]. Porto Alegre: Artmed; 2002. Original published in 2000.

American Psychiatric Association. Diagnostic and statistical manual of mental disorders $\left(\mathrm{DSM}-5^{\oplus}\right)$. 5th ed. Arlington, VA: American Psychiatric Publishing; 2013.

Beck AT, Epstein N, Brown G, Steer RA. An inventory for measuring clinical anxiety: Psychometric properties. J Consult Clin Psychol. 1988;56(6):893-7. doi:10.1037/0022-006X.56.6.893.

Beck AT, Steer RA, Brown GK. Manual for the Beck Depression Inventory-II (BDI-II). San Antonio, TX: Psychological Corporation; 1996.

Berntsen D, Rubin DC. Emotionally charged autobiographical memories across the life span: The recall of happy, sad, traumatic, and involuntary memories. Psychol Aging. 2002;17(4):636-52. doi:10.1037/0882-7974.17.4.636.

Berntsen D, Rubin DC. Emotion and vantage point in autobiographical memory. Cognition Emotion. 2006a;20(8):1193-215. doi:10.1080/02699930500371190.

Berntsen D, Rubin DC. The centrality of event scale: A measure of integrating a trauma into one's identity and its relation to post-traumatic stress disorder symptoms. Behav Res Ther. 2006b;44(2):219-31. doi:10.1016/j.brat.2005.01.009.

Berntsen D, Rubin DC. When a trauma becomes a key to identity: Enhanced integration of trauma memories predicts posttraumatic stress disorder symptoms. Appl Cogn Psychol. 2007;21(4):417-31. doi:10.1002/acp.1290.

Berntsen D, Rubin DC, Siegler IC. Two versions of life: Emotionally negative and positive life events have different roles in the organization of life story and identity. Emotion. 2011;11(5):1190-201. doi:10.1037/a0024940.

Bluck S, Alea N, Habermas T, Rubin DC. A tale of three functions: The self-reported uses of autobiographical memory. Soc Cogn. 2005;23(1):91-117. doi:10.1521/soco.23.1. 91.59198.

Boals A. Events that have become central to identity: Gender differences in the Centrality of Events Scale for positive and negative events. Appl Cogn Psychol. 2010;24(1):107-21. doi:10.1002/acp.1548.

Boals A, Hayslip B, Knowles LR, Banks JB. Perceiving a negative event as central to one's identity partially mediates age differences in posttraumatic stress disorder symptoms. J Aging Health. 2012;24(3):459-74. doi:10.1177/ 0898264311425089

Boelen PA. The centrality of a loss and its role in emotional problems among bereaved people. Behav Res Ther. 2009;47(7):616-22. doi:10.1016/j.brat.2009.03.009.

Bonanno GA, Westphal M, Mancini AD. Resilience to loss and potential trauma. Annu Rev Clin Psychol. 2011;7:511-35. doi:10.1146/annurev-clinpsy-032210-104526.

Breslau N, Kessler RC, Chilcoat HD, Schultz LR, Davis GC, Andreski P. Trauma and posttraumatic stress disorder in the community: The 1996 Detroit area survey of trauma. Arch Gen Psychiatry. 1998;55(7):626-32. doi:10.1001/archpsyc.55.7.626.

Brown AD, Antonius D, Kramer M, Root JC, Hirst W. Trauma centrality and PTSD in veterans returning from Iraq and Afghanistan. J Trauma Stress. 2010;23(4):496-9. doi:10.1002/jts.20547. 
Candel I, Merckelbach H. Peritraumatic dissociation as a predictor of post-traumatic stress disorder: A critical review. Compr Psychiatry. 2004;45(1):44-50. doi:10.1016/j.comppsych.2003.09.012.

Carlson EB. Psychometric study of a brief screen for PTSD: Assessing the impact of multiple traumatic events. Assessment. 2001;8(4):431-41. doi:10.1177/107319110100800408.

Conway MA, Pleydell-Pearce CW. The construction of autobiographical memories in the self-memory system. Psychol Rev. 2000;107(2):261-88. doi:10.1037//0033-295X.107.2.261.

Creamer M, Burgess P, McFarlane AC. Post-traumatic stress disorder: Findings from the Australian National Survey of Mental Health and Well-being. Psychol Med. 2001;31(7):1237-47. doi:10.1017/S0033291701004287.

Cunha JA. Manual da versão em português das Escalas Beck [Manual for the Portuguese Version of the Beck Scales]. São Paulo: Casa do Psicólogo; 2001.

Damasio AR. The feeling of what happens: Body, emotion and the making of consciousness. New York: Harcourt Brace; 1999.

Del-Ben CM, Vilela JA, Crippa JA, Hallak JE, Labate CM, Zuardi AW. Confiabilidade da "Entrevista Clínica Estruturada para o DSM-IV - Versão Clínica" traduzida para o português [Reliability of the structured clinical interview for DSM-IV Clinical version translated into Portuguese]. Rev Bras Psiquiatr. 2001;23(3): 156-9. doi:10.1590/S1516-44462001000300008.

First MB, Spitzer RL, Gibbon M, Williams JB. Structured Clinical Interview for DSMIV Axis I Disorders - Clinician Version (SCID-CV). Washington, DC: American Psychiatric Press; 1997.

Fiszman A, Marques C, Berger W, Volchan E, Oliveira LA, Coutinho ES, Figueira I. Adaptação transcultural para o português do instrumento Peritraumatic Dissociative Experiences Questionnaire, Versão Auto-aplicativa [Cross-cultural adaptation of the Peritraumatic Dissociative Experiences Questionnaire, SelfReport Version, to Brazilian Portuguese]. Revista de Psiquiatria Rio Grande do Sul. 2005;27:151-8.

Fivush R. The development of autobiographical memory. Annu Rev Psychol. 2011;62:559-82. doi:10.1146/annurev.psych.121208.131702.

Foa EB, Ehlers A, Clark DM, Tolin DF, Orsillo SM. The Posttraumatic Cognitions Inventory (PTCl): Development and validation. Psychol Assess, 1999;11(3):303-14. doi:10.1037/1040-3590.11.3.303

Foa EB, Hembree EA, Rothbaum BO. Prolonged exposure therapy for PTSD: Emotional processing of traumatic experiences therapist guide. New York: Oxford University Press; 2007.

Gauer G, Souza JA, Silveira AM, Sediyama CYN. Stressful events in autobiographical memory processing: Brazilian version of the Centrality of Event Scale. Psicologia: Reflexão e Crítica. 2013;26(1):98-105. doi:10.1590/ S0102-79722013000100011.

Gorenstein C, Pang WY, Argimon IIL, Werlang BSG. Manual do Inventário de Depressão de Beck - BDI-II [Manual for the Beck Depression Inventory-II (BDI-II)]. São Paulo: Casa do Psicólogo; 2011.

Kessler RC, Sonnega A, Bromet E, Hughes M, Nelson CB. Posttraumatic stress disorder in the National Comorbidity Survey. Arch Gen Psychiatry. 1995;52(12):1048-60.

Kristensen $\mathrm{CH}$. Estresse pós-traumático: Diagnóstico, prevalência e funcionamento cognitivo, Tese de Doutorado não-publicada. Porto Alegre, RS: Universidade Federal do Rio Grande do Sul; 2005.

LaBar KS, Cabeza R. Cognitive neuroscience of emotional memory. Nat Rev Neurosci. 2006;7(1):54-64. doi:10.1038/nrn1825.

Marmar CR, Metzler TJ, Otte C. The Peritraumatic Dissociation Experiences Questionnaire. In: Wilson JP, Keane TM, editors. Assessing psychological trauma and PTSD. 2nd ed. New York: Guilford; 2004. p. 144-67.

Newby JM, Moulds ML. Intrusive memories of negative events in depression: Is the centrality of the event important? J Behav Ther Exp Psychiatry. 2011;42(3):277-83. doi:10.1016/j.jbtep.2010.12.011.

Piolino P, Lamidey V, Desgranges B, Eustache F. The semantic and episodic subcomponents of famous person knowledge: Dissociation in healthy subjects. Neuropsychology. 2007;21(1):122-35. doi:10.1037/0894-4105.21.1.122.

Raes F, Hermans D, de Decker A, Eelen P, Williams JM. Autobiographical memory specificity and affect regulation: An experimental approach. Emotion. 2003;3(2):201-6. doi:10.1037/1528-3542.3.2.201.

Ribeiro WS, de Jesus Mari J, Quintana MI, Dewey ME, Evans-Lacko S, Vilete LMP, Andreoli SB. The impact of epidemic violence on the prevalence of psychiatric disorders in Sao Paulo and Rio de Janeiro, Brazil. PLoS One. 2013;8(5):e63545.
Robinaugh DJ, McNally RJ. Trauma centrality and PTSD symptom severity in adult survivors of childhood sexual abuse. J Trauma Stress. 2011;24(4):483-6. doi:10.1002/jts.20656.

Rubin DC. On the retention function for autobiographical memory. J Verbal Learn Verbal Behav. 1982;21(1):21-38. doi:10.1016/S0022-5371(82)90423-6.

Rubin DC. The basic-systems model of episodic memory. Perspect Psychol Sci. 2006;1(4):277-311. doi:10.1111/j.1745-6916.2006.00017.x.

Rubin DC, Berntsen D, Bohni MK. A memory-based model of posttraumatic stress disorder: Evaluating basic assumptions underlying the PTSD diagnosis. Psychol Rev. 2008a;115(4):985-1011. doi:10.1037/a0013397.

Rubin DC, Boals A, Berntsen D. Memory in posttraumatic stress disorder: Properties of voluntary and involuntary, traumatic and nontraumatic autobiographical memories in people with and without posttraumatic stress disorder symptoms. J Exp Psychol Gen. 2008b;137(4):591-614. doi:10.1037/a0013165.

Rubin DC, Dennis MF, Beckham JC. Autobiographical memory for stressful events: The role of autobiographical memory in posttraumatic stress disorder. Conscious Cogn. 2011;20(3):840-56. doi:10.1016/j.concog.2011.03.015.

Sbardelloto G, Schaefer LS, Justo AR, Lobo BD, Kristensen CH. Adaptation and content validation of the Brazilian version of the Posttraumatic Cognitions Inventory. Rev Saude Publica. 2013;47(2):326-34. doi:10.1590/S0034-8910. 2013047003474.

Schuettler D, Boals A. The path to posttraumatic growth versus posttraumatic stress disorder: Contributions of event centrality and coping. J Loss Trauma. 2011;16(2):180-94.

Sotgiu I, Rusconi ML. Why autobiographical memories for traumatic and emotional events might differ: Theoretical arguments and empirical evidence. J Psychol. 2014;148(5):523-47. doi:10.1080/00223980.2013.814619.

Walker WR, Skowronski JJ, Thompson CP. Life is pleasant-and memory helps to keep it that way! Rev Gen Psychol. 2003;7(2):203-10. doi:10.1037/1089-2680.7.2.203.

\section{Submit your manuscript to a SpringerOpen ${ }^{\circ}$ journal and benefit from:}

- Convenient online submission

- Rigorous peer review

- Immediate publication on acceptance

- Open access: articles freely available online

- High visibility within the field

- Retaining the copyright to your article

Submit your next manuscript at springeropen.com 